\title{
¿Y después de la guerra qué? Avatares en el tránsito a la vida civil de jóvenes desmovilizados de las FARC ${ }^{1}$
}

\author{
Luz Marina Lara Salcedo ${ }^{2}$ \\ Pontificia Universidad Javeriana, Bogotá, Colombia ${ }^{3}$ \\ laral@javeriana.edu.co \\ Recibido: 22 de mayo de 2015 \\ Aceptado: 23 de octubre de 2015 \\ Disponible en línea: 9 de mayo de 2016
}

\footnotetext{
1 Este artículo recoge algunos de los principales resultados de la investigación doctoral "Configuración de las subjetividades en el tránsito a la vida civil, de jóvenes desmovilizados de las Fuerzas Armadas Revolucionarias de Colombia-FARC”, en la línea de investigación Educación, Sujeto y Cultura del énfasis Educación, Cultura y Desarrollo del Doctorado Interinstitucional en Educación de la Universidad Pedagógica Nacional, Universidad Distrital Francisco José de Caldas y la Universidad del Valle, durante los años 2006 y 2012. La investigación no tuvo financiación y se encuentra registrada en la Vicerrectoría de Investigaciones de la Pontificia Universidad Javeriana, a la cual agradezco su apoyo para la divulgación de estos resultados.

2 Doctora en Educación

3 Docente Asociada y Directora del Departamento de Formación de la Facultad de Educación
} 


\title{
¿Y después de la guerra qué? Avatares en el tránsito a la vida civil de jóvenes desmovilizados de las FARC
}

\section{Resumen}

El artículo presenta los principales resultados de la investigación doctoral "Configuración de las subjetividades en el tránsito a la vida civil, de jóvenes desmovilizados de las Fuerzas Armadas Revolucionarias de Colombia-FARC”, con relación a los movimientos que se suscitan en la identidad, los vínculos y los valores de un grupo de jóvenes desmovilizados de las FARC. El diseño metodológico estuvo orientado a partir de las premisas centrales del socio-construccionismo y su enfoque fue narrativo. Para el trabajo analítico se abordaron los modelos arqueológicos del relato, el de trayectorias y el estructural. Los aportes derivados de este artículo buscan por un lado, abordar los escenarios de la vida civil desde su potencial emocional y por el otro, brindar comprensiones en torno al proceso de la reintegración, el papel de los ciudadanos, de la institucionalidad y de la sociedad, en la construcción del Estado que se requiere en tiempos de posconflicto.

Palabras clave: referentes de identidad; vínculos; valores; escenarios de la vida civil; escenarios emocionales; socioconstruccionismo

\section{What Comes After the War? Vicissitudes in the Change to Civilian Life of Demobilized Youths from FARC}

\begin{abstract}
This article presents the main results of the doctoral research "Configuration of Subjectivities in the Change to Civilian Life of Demobilized Youths from the Revolutionary Armed Forces of Colombia - FARC", regarding the movements provoked in the identity, ties, and morals of a group of demobilized youths from FARC. The methodological design was guided by the main premises of social constructivism, with a narrative focus. We approached the archeological, path, and structural models of the story for the analytic work. The contributions derived from this article aim to, on the one hand, address the scenarios of civilian life from their emotional potential and, on the other hand, grant some understanding around the reintegration process, the role of citizens, of institutions, and society in the construction of the State required in the post-conflict time.
\end{abstract}

Keywords: identity referent; ties; morals; scenarios of civilian life; emotional scenarios; social constructivism

\section{E depois da guerra, o que? Vicissitudes na transição para a vida civil de jovens desmobilizados das FARC}

\begin{abstract}
Resumo
O artigo apresenta os principais resultados da pesquisa de doutoramento "Configuração das subjetividades na transição para a vida civil de jovens desmobilizados das Forças Armadas Revolucionárias da Colômbia-FARC”, no que diz respeito aos movimentos que se suscitam na identidade, os vínculos e valores de uma turma de jovens desmobilizados das FARC. O desenho metodológico foi orientado a partir das premissas centrais do sócioconstrucionismo e seu enfoque foi narrativo. Para o trabalho analítico abordaram-se os modelos arqueológico do relato, de trajetórias e estrutural. Os aportes derivados deste artigo visam, por um lado, abordar os cenários da vida civil desde seu potencial emocional e, por outro, brindar compreensões em torno do processo de reintegração, o papel dos cidadãos, da institucionalidade e da sociedade, na construção do Estado que vai ser preciso em tempos de pós-conflito.
\end{abstract}

Palavras-chave: referentes de identidade; vínculos; valores; cenários da vida civil; cenários emocionais; sócio-construcionismo 


\section{Acerca del problema de investigación}

Instalarse en la vida civil implica abandonar la vida militar del grupo armado ilegal, entregar las armas, la desmovilización, dejar la clandestinidad, recuperar los derechos civiles y la búsqueda de una vida digna en la legalidad. Implica un nuevo sujeto político, nuevas maneras de actuar, de nombrarse y de reconocerse con el abandono de la identidad guerrera y la inmersión en la vida social como ciudadano, y no como adversario; implica también apertura y disposición para el diálogo y la concertación. En el paso de ese proyecto colectivo a uno individual, los referentes de identidad y pertenencia atraviesan por un proceso de reconfiguración, como fruto de los desplazamientos vividos por el sujeto y la desintegración de los vínculos afectivos, grupales y sociales hasta ahora mantenidos. El estudio buscó comprender los movimientos de la subjetividad en la experiencia que conlleva el tránsito a la vida civil de un grupo de jóvenes desmovilizados de las FARC. Para tal fin se tuvieron como categorias de análisis los referentes de identidad personal y colectiva, los vínculos, los valores y su relación con los proyectos de vida.

Con el tránsito a la vida civil comienza a emerger el vínculo con la ley social y con la institucionalidad, inaugurando una nueva relación política con los demás, con la autoridad y con el Estado. De acuerdo con Castro (2001), el verdadero tránsito a la vida civil es un paso subjetivo elaborado por cada cual y en un tiempo personal, donde los valores adquiridos desaparecen repentinamente, surgiendo un mundo de significantes sociales nuevos que invaden al sujeto.

Desde la perspectiva socio-construccionista que orientó esta investigación, lo que llamamos conocimiento no es el producto de mentes individuales, sino del intercambio social y de la interdependencia, ubicándose en una epistemología social donde "el lugar del conocimiento ya no es la mente del individuo, sino más bien las pautas de relación social" (Gergen, 1996, p.167).

Con esta lente como referente epistemológico se buscó ganar una mayor comprensión y conocimiento en torno a los movimientos 
de la identidad, los vínculos y los valores en la configuración de las subjetividades de los jóvenes, mediante el análisis de sus narrativas y cómo estas son significadas, buscando descubrir qué sucede en las lógicas subjetivas que se construyen en la experiencia de la vinculación y desvinculación.

Formar parte de un proyecto colectivo caracterizado por el sometimiento y por una disciplina militar férrea, para luego transitar desarmado hacia la vida civil, es una ruptura en la historia de vida personal, el sujeto se siente desprotegido y desamparado, siendo relevante en este contexto la construcción y el fortalecimiento de nuevos vinculos con la sociedad civil.

En este orden de ideas, se buscó comprender las transformaciones suscitadas en las subjetividades de los jóvenes en la experiencia de su reintegración a la sociedad, a partir de algunos interrogantes como los siguientes: ¿Cuáles son los desplazamientos que se han generado con respecto a los referentes de identidad personal y colectiva de los jóvenes? ¿Qué transformaciones se han producido en relación con los vinculos y los valores que han orientado sus proyectos personales y colectivos como consecuencia de la desvinculación del grupo armado?

Los aportes derivados de este artículo se sitúan por un lado, en el campo del conocimiento con relación a una mayor comprensión de las categorías identidad, vínculos y valores, y por el otro lado, en la reflexión en torno a la construcción de Estado para el periodo del posconflicto, pues los procesos de reintegración no solo comprometen a la población desmovilizada sino también a la sociedad en su conjunto y a la institucionalidad. 


\section{Referente epistemológico}

\section{El Socio-construccionismo, una perspectiva teórica y metodológica para la comprensión de la subjetividad de los jóvenes desmovilizados de los grupos armados}

El fundador de esta perspectiva fue Kenneth Gergen, quien a mediados del siglo XX hizo una reconceptualización de la psicología social y de su potencial cultural, con una propuesta renovada que evaluó el paradigma experimental vigente, a partir del crisol de la vida social. De esta manera, Gergen (1996) dio relevancia al estudio de las prácticas en el contexto social cuestionando el interés de la psicología por la predicción y el control, sus juegos de poder y sus pretensiones hegemónicas. Examinemos brevemente sus premisas.

Los términos con los que damos cuenta del mundo y de nosotros mismos tienen su origen en la cultura, la historia y el contexto social. El construccionismo social establece que el conocimiento es construido desde las prácticas socio-culturales, en contraposición al conocimiento construido por el individuo; por tanto, el conocimiento es configurado por la cultura, la historia y el contexto social, centrándose en procesos de intercambio social de narraciones definidos histórica y culturalmente. Así por ejemplo, conceptos como violencia, conflicto, excombatiente, reinsertado, desvinculado y desmovilizado, entre otros, están definidos por el uso que hacemos de ellos socialmente a través del lenguaje. De esta manera, desarrolla una epistemología social que se pregunta por la función del lenguaje en el quehacer cotidiano del intercambio social.

Los términos con los cuales comprendemos el mundo y a nosotros mismos son artefactos sociales producto del intercambio cultural e histórico entre las personas. Las descripciones y las explicaciones que damos del mundo son el resultado de la comprensión entre los hombres, sus acciones y el lenguaje, puesto que las palabras adquieren su significado en el contexto de las relaciones. Por ejemplo, los conceptos joven, conflicto, ciudadano, guerra y reintegración, varian 
en sus sentidos según determinada época histórica y cultural. Los procesos sociales que constituyen la realidad son procesos históricos y se concretizan en discursos acerca de ella, por tanto alcanzar la inteligibilidad es participar en relaciones con el pasado para encontrarle sentido al mundo.

El grado en el cual una forma de comprensión prevalece en el tiempo no depende de su validez empírica, sino de las vicisitudes de los procesos sociales. Esta premisa refleja buena parte de la historia de la tradición científica sobre los procesos sociales, con sus pretensiones de verdad, y nos invita a considerar otros procesos como la comunicación, la negociación y los conflictos en el desarrollo de las relaciones sociales a través del tiempo.

La significación del lenguaje en los asuntos humanos se deriva del modo como funciona dentro de las pautas de relación. El lenguaje gana significados a través de la interacción en los juegos del lenguaje como los llamó Wittengstein (1999), haciendo alusión a los sentidos con que se utiliza en el intercambio social. "El lenguaje es constitutivo del mundo y ayuda a generar y/o sostener ciertas formas de práctica cultural" (Estrada y Diazgranados, 2007, p.101). De esta manera, el socio-construccionismo busca una base lógica-racional para vincular la palabra con el mundo y formula que el lenguaje, en tanto sentido socialmente compartido, puede representar y reflejar el conocimiento objetivo, construir realidades y cambiar junto con las relaciones sociales. Decir que el lenguaje construye el mundo, significa que las palabras están activas en la medida que las personas las utilizan al relacionarse y en que son un poder en el intercambio humano.

Estimar las formas existentes del discurso es evaluar las pautas de vida cultural y su impacto en las relaciones humanas. Las formas de comprensión de la vida están conectadas con las actividades sociales en variedad de contextos culturales que al formar parte de contextos sociales, sirven para sostener y apoyar a algunos, excluyendo a otros; por tanto es una invitación al diálogo que evalúe las pautas de vida cultural existentes para construir una sociedad más humana, justa e incluyente. 


\section{Horizonte metodológico: el enfoque narrativo}

El diseño metodológico estuvo orientado a partir de las premisas centrales de la perspectiva socio-construccionista, razón por la cual en la investigación se abordó el enfoque narrativo con sus presupuestos metodológicos, pues lo que hace inteligible el sentido de las acciones es la explicación narrativa del sujeto sobre sus intenciones, motivos y propósitos en el horizonte de su vida. De esta manera, las narraciones de los jóvenes permitieron la comprensión e interpretación de los desplazamientos de sus referentes de identidad, vínculos y valores, a partir de los significados que construyeron, en diálogo consigo mismo y con los demás.

El proceso metodológico cubrió tres fases: 1) Producción de narrativas que comprendió tres momentos: construcción teórica del estudio; recolección de narrativas sobre el conocimiento acumulado y producido por investigadores, formuladores de politicas públicas y docentes; y recolección de relatos de vida de los jóvenes a través de entrevistas semi-estructuradas y grupos focales.

2) Análisis de las narrativas, traducido en un ejercicio de análisis reflexivo, con el fin de establecer un diálogo entre los elementos teóricos, el conocimiento acumulado por investigadores, formuladores de política pública y docentes, y las narrativas de los jóvenes. En este proceso analítico se aplicaron los tres modelos propuestos por Connick y Godard (1998): el arqueológico que buscó identificar los puntos nodales donde los relatos de vida tomaban un giro; el modelo de análisis de trayectorias el cual permitió establecer los recorridos y transiciones vividas por los sujetos, señalando los procesos que originaron cambios; y el modelo estructural que orientó la identificación de los contextos sociales con su temporalidad y las lógicas colectivas que determinaron trayectos individuales.

El tipo de análisis narrativo fue el holístico, donde los relatos de vida se tomaron como un todo, siendo cada parte interpretada en función de las restantes o en el contexto de la totalidad del relato. Para los grupos focales se aplicó el modelo de análisis conversacional, el cual 
permitió registrar los relatos en el contexto conversacional y la atención se centró en la estructura de la conversación.

3) Por último está la Interpretación de narrativas, fase que se desarrolló a lo largo de todo el proceso investigativo y correspondió al ejercicio hermenéutico, donde teoría y práctica social entraron en diálogo para producir un texto que dio respuestas a la pregunta de investigación.

\section{Población}

Para la fase de producción de narrativas intervinieron diferentes actores, entre ellos, investigadores expertos en el tema de la Universidad de Los Andes, el Observatorio de desarme, desmovilización y reintegración (DDR) de la Universidad Nacional, la Defensoría del Pueblo, la Organización Internacional para las Migraciones (OIM), formuladores de políticas públicas de la Agencia Colombiana para la Reintegración (que en su momento se denominaba Alta Consejería para la Reintegración Social y Económica, ACR) y siete docentes que se encontraban trabajando con jóvenes desmovilizados.

De igual modo, se recogieron narrativas de ocho profesionales del Programa de Apoyo Psicosocial del Centro de Servicios de la ACRIbagué, mediante la técnica de grupos focales, y se entrevistaron diez jóvenes desmovilizados pertenecientes al mismo Centro, con quienes posteriormente se realizó un grupo focal.

\section{Resultados}

Con la salida del grupo armado y el tránsito a la vida civil, los jóvenes viven un presente que se divide entre las incertidumbres del futuro y las confusiones del pasado y sus recuerdos. Podríamos decir, parafraseando a Marc Auge (1998), que en esos tiempos dificiles, pero a la vez de retornos, surge un tiempo intermedio de búsquedas, de tregua, de 
pausa, un tiempo subjetivo según Castro (2001), donde nace un sujeto que ya no es él, y otro que todavía no es.

La experiencia de los jóvenes en el tránsito a la civilidad, ese viaje que emprenden, es la inauguración de un nuevo comienzo, de búsquedas y de nuevos futuros que comprometen su subjetividad. Es un trasegar que los confronta donde su identidad deviene en una constante lucha entre la necesidad de anclaje en algún lugar de la vida civil y el escape de la vida subversiva, configurando un nuevo horizonte subjetivo que les demandará a la vez, la reconfiguración de sus vinculos y de sus valores.

A continuación se presentan los principales hallazgos relacionados con los movimientos de la identidad, los vínculos y los valores de los jóvenes desmovilizados.

\section{La transformación de los referentes de identidad}

Para iniciar el abordaje acerca de la identidad retomemos los planteamientos de Arfuch (2002), quien nos dice que toda vez que el vacío constitutivo del sujeto torna amenazador, asumiendo el carácter de una crisis de identidad, esta aparece como un escape frente a la incertidumbre y a su vez, como una afirmación ontológica en términos de 'proyecto', más que como algo definitivo o acabado. Circunstancias como un viaje, el desplazamiento, la búsqueda de otras tierras, de nuevos proyectos, de otras vidas, son motivos de esa crisis de identidad. La identidad es por tanto, una constante lucha entre la necesidad de anclaje en algún lugar y el escape de otro, una dualidad atravesada por desarraigos y temporalidades.

Adelantaremos una vía introductoria para la comprensión de la identidad, la cual se caracteriza por las posiciones cambiantes del sujeto, a través de cinco referentes que emergieron en el proceso analítico: la identidad ligada al género, al uniforme y las armas, al nombre, al reglamento y a la estigmatización. No está por demás recordar que las identidades se construyen en y a través de las relaciones sociales con 
los demás y que por tanto, la identidad se caracteriza por ser relacional, situacional y cambiante.

\section{Los cambios del referente identitario en clave de género}

El tránsito a la vida civil en el caso de muchas jóvenes, se inició con el redescubrimiento de aspectos olvidados de sus referentes de identidad femenina, pues durante el tiempo de permanencia en el grupo insurgente adquirieron nuevos referentes de identidad y pertenencia caracterizados por la masculinidad, al estar asociados a la vida militar y a las demandas de la guerra. En ese paso de un proyecto colectivo y militar a uno individual en la civilidad, dichos referentes atraviesan por una serie de reconfiguraciones que comienzan a generar afectaciones en la identidad:

Entonces ella me dijo que si me mochaba el pelo que cambiaría, y yo sí, yo le dije que sí, y yo me acuerdo que esa vez me moché el pelo bien bajito, así, que me quedara así. Y luego ella me maquilló y ya uno se ve muy diferente [...] pero yo ya con el pelo cortico me diferenciaba mucho. (Exguerrillera de las FARC. Entrevista $\mathrm{N}^{\circ} 2$ )

A propósito, nos dicen Jiménez, Muriel y Buitrago (2008) que el desprendimiento de la identidad guerrera de las jóvenes durante su tránsito a la vida civil es favorecido por el uso del maquillaje y la ropa que usan las mujeres cotidianamente, funcionando como un referente de identidad femenino muy potente y con efectos terapéuticos que favorecen la creatividad diaria y coadyuvan para que las jóvenes aprendan a verse y reconocerse como una mujer. Parafraseando a Aristizábal (2014), es un proceso de deconstrucción-reconstrucción de sus identidades que les implica asumir una nueva definición de ser mujer.

Con respecto a los jóvenes, Theydon (2005) al investigar la reconstrucción de la masculinidad y la reintegración de excombatientes en nuestro país, pone de presente que la educación, el trabajo y una vivienda digna, entre otros, son referentes simbólicos de masculinidad y de prestigio en la sociedad civil con un gran potencial para favorecer la reintegración. 
Por tanto y de acuerdo con Esguerra (2014), es necesario desarrollar programas con enfoque diferencial y en perspectiva de género que reconozcan sus experiencias en tanto sujetos de género y desde sus identidades.

\section{Del camuflado, el fusil y las botas, a los jeans y el desarme como nuevos referentes de identidad y pertenencia}

Los jóvenes pusieron en evidencia varios referentes de identidad y de pertenencia durante su permanencia en el grupo armado y, durante el tránsito a la vida civil. El primer referente mencionado fue el uniforme. Usar un uniforme, estar uniformado, hace alusión a la homogeneidad entre los miembros de un grupo, ser uno más entre los otros y con los otros. Adicionalmente, los hace identificarse y reconocerse como parte de un grupo armado al margen de la ley, inscribirse en el marco de ese colectivo y asumirse como guerreros.

De esta manera los atuendos militares, traducidos en el uniforme, las botas y el fusil, operan como referentes de pertenencia que configuran a la par una identidad guerrillera, la cual fluctúa en la vida civil de acuerdo con los modos del vestir y los accesorios propios de la mujer que les permiten verse y sentirse diferente.

De otro lado, el arma como referente de identidad otorga privilegios y masculinidad que hace que los jóvenes se sientan más hombres y con poder al interior del grupo armado, pues tener un arma es tener poder. A su vez, el arma es un referente de pertenencia al colectivo armado:

Cuando uno está pues chino como dicen, pues a uno le interesa más el cuento de las armas y todo eso. Poder tener un arma, cargarla [...] Ya al tener el arma en las manos, ya se siente que es parte del grupo, porque cualquier cosa ya van a contar con usted para lo que sea. (Exguerrillero de las FARC. Entrevista $N^{\circ} 7$ )

Es de destacar que el arma llega a convertirse en una prolongación de su cuerpo y de su fortaleza. Se puede decir que el arma se incorpora 
de tal forma en las identidades guerreras de los jóvenes, que se vuelve su brazo, su mano, un miembro más de su cuerpo. De esta manera, portar un fusil los instaura en una situación de guerra que refuerza sus procesos de identificación, definiéndolos y brindándoles un horizonte de sentido a lo que hacen.

Ahora bien, cuando los jóvenes desertaron, lo primero que hicieron tan pronto tuvieron la oportunidad fue quitarse el uniforme y cambiarse de ropa. Al des-uniformarse, simbólicamente se dan dos fenómenos: por un lado, comienzan a despojarse de esa identidad asociada al grupo armado y a la guerra; y por el otro inicia la desaparición y el desdibujo de los referentes de igualdad. Ahora se llega a una sociedad estratificada donde el estudio, el trabajo y el dinero son referentes de identidad y pertenencia que determinan necesidades y oportunidades, y donde ya no se es uniforme e indiferenciado entre los demás. Más adelante con el desarme, bien sea porque escondieron el arma o entregaron el fusil, simbólicamente dejan también la investidura de poder coercitivo, la seguridad que esta les brindaba y los significantes construidos alrededor de ella, para asumir otros referentes de poder, de sociabilidad social, que en el caso de los jóvenes está ligado principalmente a su vinculación a otros espacios y procesos familiares, educativos, laborales y productivos para poder acceder a un trabajo bien remunerado, satisfacer sus necesidades básicas y poder vivir con dignidad.

\section{El cambio de nombre como referente identitario}

Así como el cambio de nombre al ingresar al grupo armado les significó a los jóvenes un cambio en sus referentes de identidad y una ruptura en sus trayectos de vida marcando un antes y un después, con la salida del grupo y la recuperación del nombre propio también se origina otra ruptura de sus referentes identitarios con el colectivo guerrero:

Sí, eso allá se ve uno como un guerrillero, allá tiene cambiado todo, tiene que dejar las cosas que tenía buenas aparte y hasta el nombre [...] entonces ya uno empieza a ser un guerrillero. (Exguerrillero de las FARC. Entrevista $N^{\circ} 7$ ). 
Estos jóvenes dieron cuenta no solo de los nombres o 'chapas' que les fueron asignados por cuestiones de seguridad, sino también, de los modos de verse y sentirse hoy día con relación a ese otro guerrero que los habitó. En esta línea de análisis no se puede ignorar el caso de un joven que manifestó haber tenido varios nombres y con ello surge también una cadena de identificaciones en su historia subjetiva:

Mi chapa era Gago, pero eso se la cambian a uno cada mes, cada dos meses. La última fue Gago porque yo utilizaba mucho el radio y me mantenía comunicando con todos, por todas las colinas, todos los montes, todas las escuadras, pasándoles la información. La chapa más común fue Gago o Coca Cola, también me llamaban Chipichipi y El gato. Eran chapas para hablar con seguridad por la radio, porque no se podían decir nombres porque la ley interviene los radios. (Exguerrillero de las FARC. Entrevista $\mathrm{N}^{\circ} 8$ ).

Yo me llamaba Belisario Betancourt. Me pusieron ese nombre porque era el de un presidente si no estoy mal, que fue revolucionario [...] No, pues yo era un inexperto de la vida cuando a mi me pusieron ese nombre, pues uno se adapta por lo que uno es un chino y uno no sabe nada, nada. Estaba aprendiendo mejor dicho a dar los pasos de la vida. Belisario era hábil, fuerte, veloz y con una cabeza que no le entraba nada. Hoy soy sobresaliente, súper mejor, ahora por lo menos uno ya sabe para dónde va, con mejores ideas para sobrevivir, con proyectos de vida para salir adelante, si Dios quiere. (Exguerrillero de las FARC. Entrevista $\mathrm{N}^{\circ} 3$ )

\section{El reglamento como referente de identidad en el grupo armado}

Para los jóvenes el reglamento interno del grupo armado significó un referente de identidad. La razón que lo sustenta es que este obliga a pensar en un régimen, a cumplirlo y en una forma de vida disciplinada y pre-establecida por otros. El reglamento traducido en discursos, opera como un referente de identificación que a la par genera vínculos, pues con su circulación, permite generar identificaciones entre los miembros del grupo, de manera tal que el sujeto siente que forma 
parte de una causa colectiva, que se soporta además en otros referentes como la disciplina, el uniforme, las rutinas, las formas jerárquicas de la organización y los castigos, entre otros.

Con el regreso a la vida civil, los jóvenes transitan por dos tipos de reglamentos: del reglamento basado en un código normativo militar, rígido y coercitivo, a uno centrado fundamentalmente en el derecho y en una autoridad colegiada. Con esto queremos hacer cuatro señalamientos. En primer lugar, que en la vida civil los jóvenes van a encontrarse con un conjunto de reglas y procesos regulativos que por supuesto, también regulan las relaciones entre los ciudadanos; en segundo lugar que los jóvenes pasan de un régimen militarista a uno civilista, y que como en todo régimen, hay normas que buscan regular y controlar los comportamientos de las personas. En tercer lugar, que todo derecho es restrictivo y que esa regulación se da a través de procedimientos normativos, que los jóvenes entran a reconocer en los diferentes espacios donde comienzan a interactuar: en el programa de la Alta Consejeria, en el colegio, en el trabajo, en el hogar y en el barrio donde viven, principalmente. Y finalmente, que los jóvenes transitan entre dos formas de poder que van del autoritarismo a la construcción consensuada o negociada.

\section{La identidad frente al estigma del desmovilizado}

En el pasaje a la vida civil de los jóvenes desmovilizados, la construcción de referentes de identidad afines a la civilidad se ve afectada por la estigmatización. El concepto de estigma fue introducido por Goffman (1986) y sostiene que la sociedad establece medios para categorizar a las personas de acuerdo con sus atributos, lo que permite establecer su identidad social. El término estigma hace referencia a un atributo profundamente desacreditador y conlleva un doble sentido: el de los 'desacreditados', cuya condición de diferente es conocida o resulta evidente -como es el caso de los jóvenes desmovilizados-, y el de los 'desacreditables', cuya diferencia no es conocida, ni inmediatamente perceptible. 
El estigma es un rasgo sociológico que obstaculiza la interacción social y hace que nos alejemos de quien lo posee, derivando en diversos tipos de discriminación:

Porque a veces, ser desmovilizado lo perjudica a uno. En esos talleres la gente lo está mirando, y mucha gente lo distingue. La gente dice "ese que va allá, yo sé que es desmovilizado porque yo lo he visto en la ACR", entonces todo eso lo perjudica a uno [...] Pero uno a veces se hace el guevón [sic] y no le presta atención a nada. Pero lo que es en la vida laboral sí lo puede perjudicar, pues dicen "no, a ese man no le demos trabajo" y lo van como despreciando a uno [...]. (Exguerrillero de las FARC. Entrevista $N^{\circ} 3$ )

Mire que a veces sí hay gente que lo mira a uno como raro, pero al fin y al cabo ellos no dejan de ser lo mismo que es uno. Todos somos seres humanos, el hecho de que uno haya participado en una organización, entonces que lo van a mirar a uno. ¿Qué defecto tiene uno? Nada, uno es una persona, un ser humano lo mismo que el otro. Entonces ¿qué defecto? que de pronto uno fue recorrido, que si dicen que uno es malo, que uno mata, pero ¿A quién le consta que uno mata o no mata? Uno puede pertenecer a un grupo, pero ninguno ha visto que uno mató [...]. (Ex guerrillera de las FARC. Entrevista $\mathrm{N}^{\circ}$ 6)

Ahora bien, los jóvenes al percibir que los otros no los aceptan y que muchas veces no están dispuestos a establecer relaciones sociales con ellos en igualdad de condiciones, terminan por elaborar una serie de pautas de comportamiento que les permiten estar alerta frente a quienes lo rechazan; tal es el caso de los desvinculados, quienes prefieren optar por no revelar su condición en los diferentes contextos en donde interactúan:

A mí no me gusta que me llamen desmovilizada. Vea uno está en el colegio y preguntan quién es de la ACR? Y uno levanta la mano y todos voltean juch no, que fastidio!. (Exguerrillera de las FARC. Entrevista $\left.\mathrm{N}^{\circ} 4\right)$ 
Asimismo, cuando 'normales' y estigmatizados se encuentran, estos últimos descubren que se sienten inseguros sobre cómo van a ser identificados y recibidos. Su incertidumbre surge porque no saben en qué categoría serán ubicados y porque sienten que los demás pueden definirlos en función de su estigma y como vemos, pueden reaccionar con un retraimiento defensivo.

Más aun, hay que resaltar que esos sentimientos de inseguridad y miedo que embargan a los jóvenes, también se extienden a las personas de la sociedad civil, lo que sumado al estigma del desmovilizado dificulta el proceso, por los sentimientos de vergüenza que puedan llegar a albergar, debido a las reacciones de la gente:

Cuando uno se viene de allá es con miedo de la gente, cómo lo mire la gente y todo, y eso que aún todavía hay mucha gente que se da cuenta que uno es desmovilizado y de una vez como que le hacen el chai [sic].. (Exguerrillero de las FARC. Entrevista $\mathrm{N}^{\circ} 7$ )

De otra parte, las situaciones de exclusión y estigmatización manifiestas por los jóvenes nos ponen de presente la relación entre las emociones y las consecuencias derivadas del conflicto armado, cuyas expresiones de violencia desencadenan una serie de repertorios que en palabras de Strawson (1995), aluden a sentimientos morales tales como resentimiento, ira, indignación, perdón, miedo, vergüenza o solidaridad, entre otros.

\section{Devenir de los vinculos y los valores en el trasegar a la vida civil}

En este apartado nos centraremos en los cambios que se dieron en torno a los vínculos y los valores de los jóvenes desmovilizados, pues en el mundo de la vida civil comienzan a emerger relaciones vinculares en diferentes espacios que privilegian a su vez, nuevos y diferentes valores. Para tal fin, en primer lugar examinaremos la construcción de vínculos y valores de los jóvenes, durante su permanencia en el grupo armado ilegal. En segundo lugar, nos aproximaremos a la transición 
de esos vínculos y valores de los jóvenes en la sociedad civil. En tercer lugar, bordearemos los escenarios de la vida civil donde los jóvenes desmovilizados configuran nuevos vínculos y valores.

\section{A propósito de la construcción de vínculos y valores en el grupo ilegal}

La construcción de vínculos es fundamental para el soporte y la cohesión en el grupo armado. El presente estudio permitió establecer que con la vinculación, muchos de los jóvenes crearon lazos afectivos y emocionales como fruto de la convivencia, las condiciones de vida dura y de la cooperación en la vida militar.

Un referente de identificación que genera vínculo al interior del grupo armado es el discurso, pues con su circulación se generan identificaciones, de manera tal que el sujeto siente que forma parte de una causa colectiva, que se soporta además en el uniforme, en el arma, en las rutinas, en las formas de organización y en los peligros compartidos, entre otros, y esa identificación simbólica crea vínculos:

En el grupo lo tenía todo, ellos tenían buenos pensamientos, nos hablaban del derecho a la educación, a la salud, al empleo; nos decían que debíamos cuidar el agua, pues el agua es bendita. Su ideología era contra la oligarquía, nos hablaban de la igualdad para todos, que el rico debía aportar al pobre o sí no, debíamos quitarles las tierras. (Exguerrillero de las FARC. Entrevista $\mathrm{N}^{\circ} 10$ )

Estamos de acuerdo con Lara y Delgado (2010) en el llamado que hacen con relación a la relevancia de la historia previa de cada uno en su forma de vincularse al grupo armado, pues esta determina en gran parte el tejido de los vínculos y las identificaciones con el colectivo. Al igual que ellos, encontramos que así como algunos se instalan fácilmente en las lógicas de la vida militar al interior del grupo, no todos desarrollan sentidos de pertenencia, ni logran vincularse a pesar de haber estado alli. 
De otro lado, al interior del colectivo armado se promueven valores que cohesionan y fortalecen los vínculos, tales como, la disciplina, el respeto, la obediencia y la lealtad, los cuales resultan indispensables para formar parte del proyecto guerrillero y de sus formas de organización. Asimismo, esos valores otorgan un sentido a su existencia y a esa apuesta como proyecto de vida. Con respecto a los valores aprendidos los jóvenes resaltan la disciplina, el respeto, el compañerismo, la responsabilidad y la honestidad:

A mí me enseñaron la disciplina, y que uno aprende a respetar a los demás, a no ser individualista, a ser responsable, compañerista, que uno lo poquito que tiene lo aprende a compartir con los demás muchachos, eso me gustaba. Y no aprender a envolverse en problemas y chismes. Eso le enseñan a uno y uno como que lo lleva aquí adentro y eso le sirve a uno acá porque a uno le prestan algo y uno tiene que ser responsable. (Exguerrillera de las FARC. Entrevista $\left.\mathrm{N}^{\circ} 4\right)$

No tenemos duda en afirmar que el valor más apreciado por los jóvenes fue la disciplina, probablemente porque ella juega un papel central en la vida militar puesto que amortigua los temores y angustias individuales, promueve la obediencia y opera a la vez como un soporte que permite el despliegue de la fortaleza y del espíritu aguerrido que coadyuva a configurar ese cuerpo armado. No obstante, con el pasaje a la vida civil los vínculos con el grupo armado se resquebrajan, y valores como la seguridad, la solidaridad, la protección y la fraternidad desaparecen casi que instantáneamente, y el miedo a morir en combate a manos del ejército, ahora se transforma en miedo a morir en manos de sus propios compañeros, pues al desertar ya no se cuenta con el apoyo del grupo al cual pertenecían.

\section{La transición de esos vínculos y valores en la vida civil}

Una veta interesante para desplegar se refiere a esos valores que perduran y que para los jóvenes han resultado valiosos, en la creación de nuevos vínculos en el contexto de la vida civil. Al respecto, es necesario 
poner de presente que la vida civil está conformada por varios espacios sociales como el familiar, el doméstico, el productivo-laboral, el asociativo y el del ámbito de la participación política, entre otros más. En estos escenarios, a la par que los jóvenes han ido construyendo nuevos lazos sociales y afectivos, también han puesto en juego valores aprendidos en el grupo armado, tales como la responsabilidad, el respeto, la honradez y la disciplina:

Me traje conmigo más que todo la responsabilidad, primero que todo la responsabilidad pues a donde uno va tiene que ser responsable, ser honrado y a aprender a respetar a las demás personas. No me traje todo lo malo, eso lo dejé allá. Por ejemplo, los malos pensamientos sobre cómo hacerle daño a la población civil. (Exguerrillero de las FARC. Entrevista $N^{\circ} 7$ )

Como vemos, el retorno a la vida civil es un reto para los jóvenes desmovilizados, pues además de hacerse cargo de sí mismos, de hacerse a un lugar y configurar su propio 'nicho', les implica también procesos de construcción de confianza y de nuevos vínculos afectivos y emocionales con las diversas personas con quienes aprenden a interactuar en los diferentes espacios de la sociedad civil.

\section{Escenarios de la vida civil donde los jóvenes establecen pautas de relación para configurar vinculos y valores}

Como en el grupo armado, la vida en la sociedad civil también está atravesada por relaciones de control, de poder y dominación. Al interior de ella encontramos regímenes de todo tipo, razón por la cual los jóvenes terminan transitando de un marco normativo y despótico, hacia otro que también regula y normatiza, pero que intenta ser menos arbitrario.

Ahora bien, el retorno de los jóvenes a ese nuevo régimen de la vida civil, encierra formas de sociabilidad diferentes en contextos diferentes. Veamos esos escenarios a la luz de los planteamientos de Boaventura de Sousa Santos (2000), quien señala que en estos espacios se desarrollan procesos de socialización, se tejen nuevas relaciones, se establecen 
nuevos vínculos sociales y nuevos valores, se dan procesos de inclusión y de reconocimiento.

En primer lugar tenemos el espacio familiar que brinda la oportunidad de fortalecer vínculos o de crear unos nuevos al conseguir una pareja y tener hijos, generando lazos y valores paternales, afectivos, de cuidado, de seguridad y protección. De hecho, la mayoría busca contactar a sus familiares o hacer vida en pareja y tener hijos como un referente central de apoyo, siendo el vínculo familiar y afectivo un valioso soporte cargado de valores, que facilitará la nueva vida en la sociedad civil.

El espacio productivo-laboral que se caracteriza por tener una normatividad y ser jerarquizado, es un espacio al cual tendrá que ingresar el joven y posteriormente realizar un proceso de socialización laboral. En ese proceso irá estableciendo vínculos con los compañeros, con los jefes y con la institución gradualmente. Simultáneamente se dan procesos de reconocimientos sociales diferentes que se mueven en valores nuevos y diferentes como la productividad, la eficacia, la cooperación, la competitividad, el estatus y la solidaridad, pues allí también hay poderes y formas de disciplinamiento.

En el espacio escolar se construyen vínculos con el director de la institución, los profesores y los compañeros de estudio. Emergen valores como la responsabilidad escolar, el respeto, ser competente en el mundo escolar, la puntualidad, la disciplina, la tolerancia, el orden y el aseo personal, entre otros. Entonces, la creación de nuevos vínculos implica reconocer y participar en otros espacios de la vida social, donde se establecen relaciones sociales diferentes y se tejen sentidos de pertenencia diferentes.

Está el espacio comunitario, en cuyas dinámicas sociales son claves los procesos de identificación que operan con base en los orígenes comunes, el sentido de pertenencia, objetivos e intereses compartidos y los lazos sociales que se tejen. Se manifiestan a través de inclusiones o exclusiones entre sus miembros demandando una fuerte inversión emocional. Sin embargo cuando se es reconocido como miembro de la 
comunidad, surgen relaciones de reciprocidad y ayuda que los fortalecen como grupo.

De otra parte y en razón del tiempo subjetivo del que nos habla Castro (2001), no todos logran vincularse a estos espacios al mismo tiempo y pareciera que se les dificulta, pues todavia albergan sentimientos de desconfianza, miedo, inseguridad e incluso timidez:

Lo que a mí me ha ayudado es como distinguir más gente, me entiende, como distinguir gente civil, porque yo antes con gente civil casi no podia hablar o me sentía mal ¿si me entiende? Pero ahorita ya no, ahorita prefiero hablar con una persona civil [...] Sentía como falta como de confianza, yo no confío en casi nadie. Además, me daba pena, pero ahorita casi no. Antes yo no era capaz de sentarme delante de más gente, no era capaz y por eso cuando recién llegué a este proceso, uy para mí eso fue lo más dificil. (Exguerrillera de las FARC. Entrevista $N^{\circ}$ )

Probablemente tienden a ser muy reservados y distantes, tal vez, como mecanismo de defensa y de supervivencia en los nuevos contextos que les resultan extraños. En este sentido, tenemos puntos de encuentro con relación a los hallazgos de la investigación adelantada por Lara y Delgado (2010), en cuanto a que la disciplina, el respeto, la lealtad y la responsabilidad son algunos de los valores que permanecen en los jóvenes, acompañados de una actitud de desconfianza que aumenta en la vida civil, mientras establecen nuevos vínculos emocionales en ese nuevo mundo de significantes sociales en que se encuentran inmersos.

\section{Los espacios relacionales como escenarios emocionales}

El socio-construccionismo pone su acento en las relaciones sociales pues a través de ellas construimos la realidad y nos construimos socialmente. Moldear esa realidad con cualidades relacionales demanda 
generar comprensiones en los términos del lenguaje que utilizamos y desarrollar prácticas sociales que ofrezcan nuevas potencialidades a la vida cultural. En este contexto emerge el escenario relacional, aquel donde la concepción del yo y de nuestras propias acciones es dependiente de las actitudes y acciones de los demás, por tanto, nuestras formas de acción son interdependientes. Aquí, no es el individuo que piensa y luego argumenta, sino que son las formas sociales de argumentación "las que piensan al individuo" (Gergen, 1996, p. 269).

De otro lado, Gergen (1996) propone reinterpretar las emociones como acontecimientos dentro de las pautas relacionales: "como acciones sociales que derivan su significado e importancia dentro de rituales de relación" (p. 269). Bajo esta premisa los discursos que utilizamos en las pautas de relación cultural adquieren el significado de emocionales, pues gracias a la interacción las comunidades generan sus propios significados y sus propios modos convencionales de relación. Por tanto, las pautas de relación cultural pueden considerarse como escenarios emocionales, pues favorecen el intercambio social y emocional entre las personas.

De acuerdo con este planteamiento, podemos afirmar que las emociones son construcciones culturales creadas por los demás en las relaciones que construimos; de igual modo, que las emociones nos orientan frente al mundo y demuestran el tipo de relaciones que vivimos, bien sea, de alegría, de tristeza o de rabia, de donde emergen los escenarios emocionales. De esta manera podemos construir escenarios emocionales de empatía, felicidad, acogida y respeto, en escenarios como la familia, la institución educativa, el trabajo y la comunidad, los cuales son a su vez escenarios de la vida civil, teniendo como telón de fondo los derechos humanos para la construcción de la dignidad y de nuevas formas de ciudadanía. 


\section{A manera de cierre}

En los escenarios emocionales el eje central es la creación y el fortalecimiento de vínculos, permeados por valores como la confianza, el reconocimiento, el respeto, la solidaridad y la participación entre los jóvenes y las comunidades receptoras, en un proceso de doble vía. Se trata de abandonar palabras como desmovilizado, desvinculado, reinsertado, victimario, víctima y enemigo, entre otras; y cambiarlas por ofensor, ofendido y afectado como propone Molina Valencia ${ }^{4}$ (2010); y de recuperar palabras como dignidad, acogida, aceptación, confianza pues a fin de cuentas, el mundo social es una construcción que se basa en significados y estos se construyen en las relaciones.

Los ámbitos educativo y comunitario como espacios de socialización secundaria, implican la internalización y el aprendizaje de un conjunto de referentes y de repertorios sociales y culturales donde se construyen comunidades de aprendizaje, que a la vez permiten establecer relaciones sociales portadoras de sentidos y significados compartidos, los cuales configuran la noción de un nosotros, sobre la base de compartir objetivos comunes, valores, símbolos, vocabularios y normas que posibilitan el reconocimiento y el sentido de pertenencia. La riqueza de estos escenarios también radica en que los valores compartidos en estos ámbitos, promueven la cooperación como una forma de construcción de acuerdos para el bien común; el respeto a la diferencia o capacidad para ejercer el derecho a la crítica, a la controversia, a pensar diferente y la solidaridad, relacionada con la empatía y el apoyo mutuo para favorecer la convivencia social.

El conflicto armado ha construido un escenario relacional de desconfianza, imposición, arbitrariedad, control y sometimiento que es necesario deconstruir para pensar en nuevos escenarios en los que podamos reconocernos, partiendo de la creación de nuevos vínculos

\footnotetext{
4 Molina sugiere que el cambio de categorias para nombrar los actores transforma su propia comprensión y la del conflicto. En este sentido el conflicto no depende solamente de la relación entre dos o más actores que han generado una disputa, sino de todos los actores que causan daño, son dañados y potencialmente podrían sufrirlo. Así las cosas, el conflicto es una relación entre actores (p. 67).
} 
sociales que nos permitan 'desmovilizarnos' también frente a los actores de la guerra.

\section{Referencias}

Aristizábal, L. (2014). Devenir civil/Devenir mujer: una mirada a las subjetividades de mujeres excombatientes en proceso de reinserción. En Centro Nacional de Memoria Histórica - Dirección de Acuerdos de la Verdad. Desafios para la reintegración. Enfoque de género, edad y etnia (pp. 212-258). Bogotá: Imprenta Nacional.

Arfuch, L. (2002). El espacio biográfico. Dilemas de la subjetividad contemporánea. Buenos Aires: Fondo de Cultura Económica.

Auge, M. (1998). Las formas del olvido. Barcelona: Editorial Gedisa.

Castro, M. C. (2001). Del ideal y el goce. Lógicas de la subjetividad en la vía guerrillera y avatares en el paso a la vida civil. Bogotá: Universidad Nacional de Colombia.

Coninck, F. y Godard, F. (1998). El enfoque biográfico a prueba de interpretaciones. Formas temporales de causalidad. En Lulle, Vargas y Zamudio (Eds.). Los usos de la historia de vida en las ciencias sociales, Vol. II. (pp. 250-269). Bogotá: Anthropos.

De Sousa Santos, B. (2000). Crítica de la razón indolente. Contra el desperdicio de la experiencia. Para un nuevo sentido común: la ciencia, el derecho y la política en la transición paradigmática. Volumen 1. España: Editorial Declée de Braver.

Esguerra, J. (2014). Desarmando las manos y el corazón: Transformación en las identidades de género de excombatientes. En Centro Nacional de Memoria Histórica-Dirección de Acuerdos de la Verdad. Desafios para la reintegración. Enfoque de género, edad y etnia (pp.135-211). Bogotá: Imprenta Nacional.

Estrada, A. y Díazgranados, S. (2007). Kenneth Gergen: Construccionismo Social. Aportes para el debate y la práctica. Bogotá: Universidad de Los Andes. 
Gergen, K. (1996). Realidades y relaciones. Aproximaciones a la construcción social. Barcelona: Paidós.

Goffman, E. (1986). Estigma. La identidad deteriorada. Madrid: Amorrortu Editores.

Jiménez, C., Muriel, A.M. y Buitrago, H. A. (2008). Narrativas de construcción de la dignidad. Módulo I. Bogotá: Defensoría del Pueblo Delegada para los Derechos de la Niñez, la Juventud y la Mujer.

Lara, L. M y Delgado, R. (2010). Trasegar de las subjetividades y las memorias de las y los jóvenes desmovilizados en el tránsito a la vida civil. Una mirada a los programas educativo y de apoyo psicosocial. Revista Universitas Humanística, (70), 29-56.

Molina, N. (2010). Reconstrucción de memoria en historias de vida. Efectos políticos y terapeúticos. Revista de Estudios Sociales de la Universidad de Los Andes (36), 64-75.

Strawson, P. (1995). Libertad y resentimiento. Barcelona: Paidós.

Theydon, K. (2005). La reconstrucción de la masculinidad: el desarme, la desmovilización y reintegración de excombatientes en Colombia. Human Right Quarterly, 31(1), 22-24.

Wittengstein, L. (1999). Investigaciones filosóficas. Gran Bretaña: Ediciones Prentice Hall.

\section{Cómo citar este artículo}

Lara, L. M. (2016). ¿Y después de la guerra qué? Avatares en el tránsito a la vida civil de jóvenes desmovilizados de las FARC. Universitas Humanística, 82, 49-73. http://dx.doi.org/10.11144/Javeriana.uh82.dgat 